\title{
Study of efficacy and safety of levosalbutamol versus racemic salbutamol delivered by metered dose inhaler in children with moderate persistent asthma
}

\author{
Sharma S. ${ }^{1}$, Mathew J.L. ${ }^{2}$, Singh M. ${ }^{3}$ \\ ${ }^{1}$ Dr. Sarita Sharma, Consultant Pediatrician, Department of Paediatrics and Neonatology, Fortis FLt Lt Rajan Dhall \\ Hospital, Vasant Kunj, ${ }^{2}$ Dr. Joseph L. Mathew, Professor, ${ }^{3}$ Dr. Meenu Singh, Professor, Department of Paediatrics and \\ Neonatology, PGIMER, Chandigarh, India.
}

Corresponding Author: Dr. Sarita Sharma, Consultant Paediatrician, Department of Paediatrics, Fortis FLt Lt Rajan Dhall Hospital, Vasant Kunj. Email: drsaritasharma@outlook.com

\begin{abstract}
Aim: To compare the efficacy and safety of Levosalbutamol versus racemic Salbutamol delivered by metered dose inhaler in children with moderate persistent asthma. Materials and Methods: Children enrolled in the study were randomized to receive MDI Levosalbutamol 2 puff thrice daily, $50 \mu \mathrm{gm} /$ puff (group A) or MDI Racemic Salbutamol 2 puff thrice daily. $100 \mu \mathrm{gm} /$ puff (group B).Baseline characteristics of both groups were comparable. The $\mathrm{FEV}_{1} \%$ and $\mathrm{PEF} \%$ were assessed at baseline, at 15 minutes following the first dose on day 1 and on day 8. In children who remained symptomatic on day 8 , an additional evaluation on day 15 was performed. Asthma symptom score were calculated from symptom score card. Results: There was significant improvement in PEF \% and $\mathrm{FEV}_{1} \%$ within each group. But there was no statistically significant inter-group difference in PEF \% change and $\mathrm{FEV}_{1} \%$ change except mean change in PEF $\%$ and $\triangle \mathrm{PEF} \%$ of initial on day 8 (at the end of 1 week). Asthma symptom score improved significantly in both groups but there was no inter group difference. Incidence of side effects like decrease in serum potassium level and increase in heart rate were comparable in between the two groups. Conclusion: Levosalbutamol administered via MDI improved $\mathrm{PEF} \%$ significantly more in comparison of racemic Salbutamol after regular use of one week. However, no significant differences were observed in between the two drugs with respect to pulmonary function test on day 1 , FEV $\%$ on day 8 and asthma symptom score. The side effect profile of the two drugs was comparable. This suggests that Levosalbutamol is at least as efficacious as conventional Salbutamol in terms of clinical efficacy.
\end{abstract}

Keywords: Levosalbutamol, Racemic salbutamol, Metered dose inhaler, Moderate persistent asthma

\section{Introduction}

Inhaled short acting $\beta_{2}$ agonists are used as medication in management of bronchial asthma. Of these, Salbutamol is the most widely prescribed drug. With the availability of advanced technology to separate the two enantiomers of $\beta_{2}$ agonist, the role of S-Salbutamol has been challenged recently, fueled in part by controversies about the possible deleterious effects of $\beta 2$ agonists as well as the FDA's mandate to quantify the risks of stereoisomeric drugs (S) Salbutamol has been found to potentiate airway obstruction and the development of airway hyper-responsiveness by exerting direct effect on airway smooth muscle. Further, recent in vitro studies have shown that (S)

Manuscript received: $20^{\text {th }}$ May 2019

Reviewed: $30^{\text {th }}$ May 2019

Author Corrected: $7^{\text {th }}$ June 2019

Accepted for Publication: $13^{\text {th }}$ June 2019 enantiomer increases intracellular calcium in airway smooth muscle cells which promotes smooth muscle contraction and opposes bronchodilation. It has also been shown to have some pro inflammatory properties. These findings suggest that (S) enantiomer is a non $\beta_{2}$ agonist bronchoconstrictor that is inhibited or masked by bronchodilating action of $(\mathrm{R})$ enantiomer [1,2].

With the availability of Levosalbutamol in pure active form, a number of studies have been done comparing the efficacy and safety of Levosalbutamol to racemic Salbutamol. Compared to adults there are only few studies that have been done in pediatric population comparing Levosalbutamol and racemic Salbutamol. These studies have compared drug delivered in nebulizer formulation and there is no data comparing 
these drugs in metered dose inhaler formulations which is convenient, cheap and easy to deliver [3,4]. Considering the need of longer duration of treatment with $\beta_{2}$ agonists and frequent use of these drugs in children with asthma a study comparing these drugs delivered in pressurized metered dose inhaler formulation in pediatric patients is mandated. Hence, this randomized controlled trial was undertaken in children with moderate persistent asthma to assess the efficacy and safety of Levosalbutamol in comparison with racemic Salbutamol (both delivered by pressurized metered dose inhaler) using objective and subjective outcome measures [5].

\section{Methodology}

This randomized controlled trial was conducted after clearance from Institute Ethics Committee. A total of 97 subjects were enrolled with the written, informed consent of parents and consent of children themselves. Enrollment was undertaken from the children attending Asthma/Allergic Clinic of the Department of pediatrics.

\section{Inclusion Criteria}

1.Children in the age range 6 to 14 years with

2.Physician diagnosed moderate persistent asthma presenting with baseline $\mathrm{FEV}_{1} \%$ or $\mathrm{PEF} \%$ (in case of those children unable to perform spirometry) between $50 \%$ and $80 \%$ of the predicted for age or personal best where available and symptomatic (cough, wheezingetc).

\section{Exclusion criteria}

1. Known hypersensitivity to Salbutamol.

2. Significant concurrent disease such as tuberculosis, cystic fibrosis, kyphoscoliosis and history of upper or lower respiratory tract infection during the preceding 4 weeks.

3. Associated congenital heart disease.

4. Received oral or parenteral steroid therapy, theophylline or other broncho dilators, leukotriene modifier, cromolyn 01 nedocromil sodium within 30 days prior to presentation.

\section{Respiratory distress at presentation}

In order to detect an effect size of $10 \%$ difference in the $\mathrm{PEF} \%$ or $\mathrm{FEV}_{1} \%$ between the two treatment arms, with an alpha error of 0.05 and power of $80 \%$ the smallest number of subjects to be included in this study was 88. However, a total of 97 subjects were enrolled.
Subjects were randomized using computer generated random number table and allocated into either of two groups using opaque sealed covers - Group A received 2 puffs of Levosalbutamol (5O $\mu$ gm per puff), through metered dose inhaler (with spacer), while group B received 2 puffs of racemic Salbutamol (100 $\mu \mathrm{g}$ per puff) through metered dose inhaler (with spacer).

A detailed history was elicited from each subject with special reference to history of symptoms, personal history, history of known allergies and family history. Each child underwent a thorough physical examination including anthropometric measurement, general examination and systemic examination. Children and parents were given education regarding the condition and training for inhalation therapy was reinforced.

Baseline PEF was recorded in all children $\mathrm{FFV}_{1}$ was measured in 31 children who could perform spirometry as per the recommendations of the American Thoracic Society and PEF was measured by Mini Wright's Peak Flow Meter and percentage calculated against the expected predicted as per Indian norms.

The Asthma Symptom Score was calculated at baseline by asking the children/caregiver regarding the following specific symptoms during the preceding seven days viz history of day time cough, history of nocturnal cough, missing of school, wheezing, difficulty in breathing and limitation of activity. A score of zero was given for absence and one for the presence of each of the items. The total Asthma Symptom Score (out of 42) was recorded.

At enrollment (Day 1) pre and post $\mathrm{FEV}_{1} \%$ and $\mathrm{PEF} \%$ of the subject were compared before and after fifteen minutes of inhalation of the drug. This was followed by advice to continue 2 puffs thrice daily (up to a maximum of 8 puffs per day if symptoms persisted) for a period of one week. The inhaled corticosteroid prescribed was continued in the same dosage and frequency.

Children were given asthma symptom score cards to mark at home. The symptom diary was reviewed at each visit and total score was calculated and recorded. Both groups were re-assessed at the end of first week (Day 8 ) and their pulmonary function test (PEF\% and $\left.\mathrm{FEV}_{1} \%\right)$ were recorded. Children who were symptomatic on day 8 were required to attend another follow up visit for clinical evaluation on day 15 . They were advised to continue the respective drugs during this period. At each visit, history and examination for tremor and tachycardia/palpitation were done. 


\section{Original Research Article}

Outcome measures- The primary outcome variable was the mean $\mathrm{FEV}_{1} \%$ or PEF \% change (in those children unable to perform spirometry) measured on Day 8 after starting the intervention.

Secondary outcome variables were $\mathrm{FEV}_{1} \%$ and PEF \% change measured on Day 1 (post bronchodilator) and

\section{Results}

In group A improvement in pulmonary function test was noticed following the medication. Mean PEF \% change ( $\mathrm{n}=4 \mathrm{~S}$ ) on dayl was $14.61 \pm 7.4$.This change was significant $(\mathrm{p}<0.05)$. Similarly mean PEF\% change on day $8(n=48)$ was $19.71 \pm 7.2(\mathrm{p}<0.05)$. Out of 48 children only 3 required medication regularly for 2 weeks. At end of $2^{\text {nd }}$ week mean change in $\mathrm{PEF} \%$ was $22.15 \pm 10.9$.

In group B also improvement in pulmonary function test was noted following medication. Mean PEF \% change ( $\mathrm{n}=45$ ) on dayl was $12.83 \pm 7.5$. This change was significant $(\mathrm{p}<0.05)$. Similarly mean PEF \% change on day $815.57 \pm 7.48$ $(\mathrm{p}<0.05)$. Out of 45 children, only 2 required continuation of medication for 2 weeks. On day 15 mean PEF $\%$ change was $13.58 \pm 8.6$. In group B 16 children were able to perform spirometry. Mean $\mathrm{FEV}_{1} \%$ on day 1 following medication was 8.67 \pm 4.06 , while on day 8 change in mean $\mathrm{FEV}_{1} \%$ was $11.76 \pm 6.8(\mathrm{p}<0.05)$.

Statistical analysis: The mean and standard deviation of $\mathrm{FEV}_{1} \%$ and $\mathrm{PEF} \%$ were calculated at baseline, post bronchodilator on Dayl and on Day 8 (at the end of first week) and Day 15 (at the end of second week) for each group. Independent sample $t$ test was used to compare change in PEF \% and FEVondayl, day8 and day 15 of starting medication. To evaluate the efficacy of individual drug Paired t test was used. Weekly asthma symptom score was compared at baseline, on day 8 and dayl5. Mean serum potassium was compared at baseline and on day 8 (at the end of first week) of enrollment. The means were compared using Student $t$ test as the distribution was Gaussian. Proportion of children manifesting tachycardia and hypokalemia in each group were compared using Chi square test', p value of $<0.05$ was defined as significant.

Table -1: Baseline pulmonary function tests and asthma symptom score

\begin{tabular}{|c|c|c|c|c|c|c|c|c|c|c|}
\hline \multirow[t]{2}{*}{ Parameters } & \multicolumn{4}{|c|}{ Group A } & \multicolumn{4}{|c|}{ Group B } & \multirow{2}{*}{$\begin{array}{c}\mathbf{t} \\
\text { value }\end{array}$} & \multirow{2}{*}{$\begin{array}{c}P \\
\text { value }\end{array}$} \\
\hline & $\mathbf{N}$ & Mean & SD & $\begin{array}{l}95 \% \mathrm{Cl} \text { of } \\
\text { mean }\end{array}$ & $\mathbf{n}$ & Mean & SD & $\begin{array}{c}95 \% \mathrm{Cl} \text { of } \\
\text { mean }\end{array}$ & & \\
\hline PEF\% & 48 & 69.65 & 7.5 & $67.4-71.8$ & 45 & 69.84 & 7.09 & $67.7-71.9$ & 0.13 & 0.90 \\
\hline $\mathrm{FEV}_{1} \%$ & 15 & 66.96 & 6.9 & $63.0-70.8$ & 16 & 63.5 & 8.07 & $59.2-67.8$ & 1.26 & 0.215 \\
\hline ASS & 48 & 16.8 & 5.6 & $15.2-18.4$ & 45 & 17.3 & 5.4 & $15.7-18.9$ & 0.433 & 0.666 \\
\hline
\end{tabular}

Table-2 Mean PEF\% change over baseline in between the two groups

\begin{tabular}{|c|c|c|c|c|c|c|c|}
\hline \multirow[t]{2}{*}{ Parameter } & \multicolumn{2}{|c|}{ Group A $(n=48)$} & \multicolumn{2}{|c|}{$\begin{array}{c}\text { Group B } \\
(11=45)\end{array}$} & \multirow[t]{2}{*}{$\begin{array}{c}95 \% \text { Cl Of } \\
\text { (he difference) }\end{array}$} & \multirow[t]{2}{*}{$\begin{array}{c}\text { t } \\
\text { value }\end{array}$} & \multirow[t]{2}{*}{$\begin{array}{c}\mathbf{P} \\
\text { value }\end{array}$} \\
\hline & Mean & SD & Mean & SD & & & \\
\hline $\begin{array}{c}\text { Mean PEF Percent } \\
\text { change on day } 1\end{array}$ & 14.61 & 7.41 & 12.83 & 7.53 & $-1.2-4.8$ & 1.14 & 0.253 \\
\hline $\begin{array}{l}\text { Mean PEF Percent } \\
\text { change on day } 8\end{array}$ & 19.71 & 7.23 & 15.57 & 7.48 & $1.1-7.17$ & 2.711 & 0.008 \\
\hline
\end{tabular}

There was significant improvement in $\mathrm{PEF} \%$ and $\mathrm{FEV}_{1} \%$ within each group. But there was no statistically significant inter- group difference in PEF \% change and $\mathrm{FEV}_{1} \%$ change except mean change in $\mathrm{PEF} \%$ and $\triangle \mathrm{PEF} \%$ of initial on day 8 (at the end of 1 week). 
Table-3: Reversibility in Study Groups.

\begin{tabular}{|c|c|c|c|}
\hline Parameters & Group A & Group B & p value \\
\hline Reversibility & $25(52.1 \%)$ & $21(46.7 \%)$ & 0.602 \\
(change in PEF\% $>12 \%$ on dayl) & $\mathrm{n}=48$ & $5(31.3 \%) \mathrm{n}=16$ & 0.474 \\
\hline $\begin{array}{c}\text { Reversibility } \\
\text { (change in } \mathrm{FEV}_{1} \%>12 \% \text { on dayl) }\end{array}$ & $3(20 \%) \mathrm{n}=15$ & & \\
\hline
\end{tabular}

Table-4: Mean asthma symptom score change.

\begin{tabular}{|c|c|c|c|c|c|c|c|c|}
\hline Parameter & \multicolumn{3}{|c|}{ Group A } & \multicolumn{3}{c|}{ Group B } & t & P \\
\cline { 1 - 7 } $\begin{array}{c}\text { Change in asthma } \\
\text { symptom score }\end{array}$ & $\mathrm{N}$ & mean & $\mathrm{SD}$ & $\mathrm{n}$ & mean & $\mathrm{SD}$ & value & Value \\
\cline { 2 - 9 } & 48 & 13.95 & 4.6 & 45 & 12.93 & 5.6 & 0.957 & 0.341 \\
\hline
\end{tabular}

Asthma symptom score improved significantly in both groups but there was no inter group difference. Incidence of side effects like decrease in serum potassium level and increase in heart rate were comparable in between the two groups.

Table-5: Tachycardia on follow up in two study groups

\begin{tabular}{|c|c|c|c|c|}
\hline \multirow{2}{*}{ Age group } & \multicolumn{2}{|c|}{ Group A } & \multicolumn{2}{c|}{ Group B } \\
\cline { 2 - 5 } & Normal & Tachycardia & Normal & Tachycardia \\
\hline $6-7$ years & 12 & 5 & 11 & 5 \\
\hline $8-10$ years & 15 & 1 & 12 & 4 \\
\hline $11-14$ years & 13 & 2 & 12 & 1 \\
\hline
\end{tabular}

Mean heart rate in age subgroup 6-7 years on follow up in group A was 110.5 \pm 18.2 , while in group B it was $110.8 \pm 11.7$. Mean heart rate in subgroup 8-10 years and 11-14 years in group A on follow up were 99.5 \pm 7.9 and 93.7 \pm 6.6 , while in group B these were $101.4 \pm 8.01$ and $100.3 \pm 11.1$ respectively. Mean heart rate in between the two study groups on follow up were comparable ( $>>0.05)$. One of the children in group A manifested severe palpitation with heart rate recorded up to $176 /$ min requiring discontinuation of medication.

Table-6: Mean serum potassium in between the two groups.

\begin{tabular}{|c|c|c|c|c|c|c|}
\hline Parameter & \multicolumn{3}{|c|}{ Group A(n=48) } & \multicolumn{3}{c|}{ Group B (n=45) } \\
\hline Serum K+ On day 8 & Mean & SD & $95 \%$ Cl of mean & Mean & SD & $95 \%$ Cl of mean \\
\cline { 2 - 8 } & 3.96 & 0.38 & $3.85-4.07$ & 3.89 & 0.37 & $3.78-4.00$ \\
\hline
\end{tabular}

\section{Discussion}

Salbutamol is the most widely used $\beta-{ }_{2} 2$ agonist for relief of bronchospasm in asthma. The formulation in common use is a 50:50 mixture of two mirror image enantiomers termed (R) and (S) Salbutamol. It was demonstrated in several pharmacological studies bronchodilator activity of drag is attributed to (R) isomer, while ( $\mathrm{S}$ ) isomer is considered as biologically inert. However, role of (S) Salbutamol has been challenged as not being only inert filler but also being responsible for number of side effects observed with the drug[4,5,6].
In the present randomized controlled study efficacy and safety of Levosalbutamol and racemic Salbutamol were compared in children aged 6-4 years who had moderate persistent asthma with symptoms requiring rescue medication delivered by pressurized metered dose inhaler. A dose of $50 \mu \mathrm{gm}$ of Levosalbutamol was compared to $100 \mu \mathrm{gm}$ of racemic Salbutamol, both delivered by pressurized metered dose inhaler. Change in the pulmonary function test expressed as percentage of initial also showed significant difference between the two groups on day 8 of study $(\mathrm{p}<0.05)$ These finding 
suggest that $50 \mu \mathrm{gm}$ of Levosalbutamol produces similar or better bronchodilator response compared to $100 \mu \mathrm{gm}$ racemic Salbutamol. Subjects in both the groups improved symptomatically with corresponding decrease in asthma symptom score on day 8 . However, no statistically significant difference was noted in between the groups $(\mathrm{p}>0.05)$.

Nelson et al, conducted a study in adult patients with chronic asthma, demonstrated that lower doses of Levosalbutamol delivered by nebulizer is equally or more efficacious than higher doses of racemic Salbutamol. Nelson et al conducted the first major multicenter, randomized, double blinded, placebocontrolled, parallel-group study on adolescent and adult patients with moderate to severe persistent asthma. They randomized subjects to receive one of the following nebulized treatments $-0.625 \mathrm{mg}$ of Levosalbutamol, $1.25 \mathrm{mg}$ of Levosalbutamol, $1.25 \mathrm{mg}$ of racemic Salbutamol, $2.5 \mathrm{mg}$ of racemic Salbutamol and placebo. Medications were given three times daily for 28 days. Serial pulmonary function tests were done at baseline, 2 and 4 weeks. The mean peak percentage change in $\mathrm{FEV}_{1}$ at the baseline but not at 4 weeks was significantly greater in the combined Levosalbutamol group compared to combined racemic Salbutamol group.

This pioneering study has several differences from the present study. In the current study children received medication for one week but were advised to continue for another one week only if symptoms persisted beyond day 8 . This is thus more consistent with the usual asthma management protocol in children. In Nelson's study, effect of chronic dosing of drugs were also evaluated by comparing mean pre-dose $\mathrm{FEV}_{1}$, at week 4 to baseline for all patients and for a subset of patients who did not receive inhaled corticosteroids.

This evaluation was not done in the current study since rescue medication for longer period than necessary was not used. Nelson's study demonstrated change in heart rate after dosing was significantly lower in the $0.63 \mathrm{mg}$ Levosalbutamol arm than in the $2.5 \mathrm{mg}$ racemic Salbutamol arm $(\mathrm{p}<0.05)$ suggesting a dose response effect. It is therefore notable that the lowest possible dosage of the $\beta_{2}$ against drugs. However, the dose related side effects like nervousness and tremor as reported in Nelson study were not seen in the current study [7].

Lotvallet al and Handley et al also studied separately the efficacy and safety profile of Levosalbutamol compared to racemic Salbutamol in adults. No walk et al in a study on adults with acute asthma concluded that Levosalbutamol administered in nebulizer formulation produced comparable effects to the higher doses of Racemic salbutamol. A few other studies in adults, such as one done by Lotvall et al, demonstrated a dose related improvement in pulmonary function test with Levosalbutamol.

Lotvall et al has concluded that side effects depend on (R) Salbutamol only, consistent with the finding in the current study. Nowak et al in a randomized, double blinded, multicentre study on adults showed Levosalbutamol accelerates improvement in $\mathrm{FEV}_{1}$ compared to racemic Salbutamol. But this study included adults with acute asthma compared to the current study which has been done in children with moderate persistent asthma $[8,9,10]$.

Milgrom et al, in a randomized, double blinded, multicentre, parallel group study conducted on 338 children in age range of 4-11 years showed that Levosalbutamol was clinically comparable to 4-8 fold higher doses of racemic Salbutamol when delivered by a nebulizer. Side effects observed with Levosalbutamol were comparable or less than that observed with racemic Salbutamol. Milgrom et al showed that more patients experienced a decrease in serum potassium in racemic Salbutamol $2.5 \mathrm{mg}$ group (25\%) as compared to $0.31 \& 0-63 \mathrm{mg}$ of Levosalbutamol groups. In the present study, of the 48 children in 50 pgm Levosalbutamol group $4.1 \%$ experienced hypokalemia, while in racemic Salbutamol $100 \mathrm{pgm}(\mathrm{n}=45)$ this figure was $8.8 \%$. The difference noted in the increase of heart rate in between the two study groups in the current study which is consistent with the finding in Milgrom's study [11].

Maiti et al and Gawchik et al concluded that Levosalbutamol causes a significantly greater increase in pulmonary function test results than placebo and FEV; values were comparable or better than that observed with racemate. Gawchik et alhas compared 4 doses (0 $16 \mathrm{mg}, 0.31 \mathrm{mg}, 0.63$ and $1.25 \mathrm{mg}$ ) of racemic Salbutamol with placebo in 33 children with chronic stable asthma in a randomized, double blinded single dose, crossover study. Although this study demonstrated lower doses of Levosalbutamol to be as efficacious as higher doses of racemic Salbutamol, it is a single dose study where subjects were administered single dose of drug on 4 treatment visits each separated by 2 to 8 days interval. The current study did not conducted observations to explore the effect of chronic dosing of drugs. Also, number of subjects in this study is small compared to the current study $[12,13]$. 
Jantikar et al conducted a recent study comparing these two drug formulations delivered by metered dose inhaler in a group of adult patients and concluded that a single dose of Levosalbutamol produces equivalent time dependent bronchodilator response over 6 hours as compared to racemic Salbutamol at half the dose. The primary outcome variable in this study was the mean difference in area under the curve for percent change in $\mathrm{FEV}_{1}$ and FVC from baseline to 6 hours. However, this study has compared the effect of single doses of drugs in a very small number of subjects.

They evaluated safety profile of the MDI formulations of the two drugs and demonstrated that both produce significant decrease in serum potassium and increase in heart rate 1 hour after the stud) drug administration. They concluded that systemic side effects of Salbutamol reside with $(\mathrm{R})$ enantiomer. This is again similar to what we found in the current study. This study demonstrated that bronchodilator effect and systemic side effects of Salbutamol reside with $(\mathrm{R})$ enantiomer [14].

Ameredes BT et al in an experimental study has shown that (S) Salbutamol enhances granulocyte macrophage colony stimulating factor production. This cytokine leads to increased proliferation of smooth muscle cells as well as proliferation and migration of inflammatory cells. This finding might explain the pro inflammatory cytokine environment seen in asthmatic airway (S) Salbutamol may further contribute to airway obstruction by increasing pulmonary vascular endothelial and epithelial permeability, based on the observed in vivo effect of (S) Salbutamol in animal model of pulmonary inflammation[15].

There were no details of treatment related serious adverse effects. In this study it was observed that both Levo and racemic Salbutamol led to decrease in serum potassium level from baseline value over the study period and number of subjects who developed hypokalemia in former group was 2 , while in latter it was 4. However, this decrement in mean serum potassium level and incidence of hypokalemia was not statistically significant $(p>0.05)$ between the two groups.

The observations and results in our study are in agreement with limited number of previous studies which have shown that pure $\mathrm{R}$ isomer in the absence of (S) Salbutamol, results in efficacy that is clinically comparable to higher doses of the racemate. However, this randomized controlled trial conducted on children with moderate persistent asthma is a unique kind for pediatric population as there was no previous study comparing Levosalbutamol and racemic Salbutamol delivered in pressurized metered dose formulations in pediatric patients when this research was initiated. The study done has explored many positive aspects in terms of appropriate study design, precisely defined enrollment criteria, strict follow up, minimal dropouts, excellent drug compliance and adequate power for primary variables. In the current study both subjective and objective variables were taken for evaluation. However, in the present study pharmacokinetic analysis of drugs were not undertaken due to technical limitations and the study was not blinded.

\section{Conclusion}

The results show that both the drugs were efficacious in ameliorating symptoms attributable to asthma and led to significant improvement in lung function test. This was observed both on day 1 following first dose as well as on day 8 of therapy. A significant proportion of patients in each group responded to medications (improvement in pulmonary function test of $>12 \%$ ) on day of enrollment, $52.1 \%$ in Levosalbutamol group and $46.7 \%$ in racemic Salbutamol group respectively.

Though the mean PEF \% change and $\mathrm{FEV}_{1} \%$ change in Levosal-butamol group was more compared to racemic Salbutamol group on day 1 and day 8 both, statistically significant difference was observed only in mean PEF $\%$ change on day 8 of therapy.

The side effect profile of the two drugs was comparable and 110 major adverse effects were noted in most of the subjects. This suggests that Levosalbutamol is at least as efficacious as conventional Salbutamol in terms of clinical efficacy.

It will be worthwhile to advance this study further by a dose ranging of Levosalbutamol, to find the smallest efficacious dose. It may also be useful to assess patient preference for either drug by incorporating additional measurement such as quality of life score.

\section{Funding: Nil, Conflict of interest: None initiated, Permission from IRB: Yes Ethical approval: Taken}

What This Study Add to Existing Knowledge? This randomized controlled trial conducted on children with moderate persistent asthma is a unique kind for pediatric population as there was no previous study comparing Levosalbutamol and racemic Salbutamol delivered in pressurized metered dose formulations in pediatric patients when this research was initiated. 


\section{Contribution by Different Authors}

First and Corresponding Author: Dr. Sarita Sharma: Concept and design of the study.

Second Author: Dr. Joseph L Mathew: Data collection and arrangement of references

Third Author: Dr. Meenu Singh: Supervision of the study

\section{References}

1. Chaudry I, Banerjee P, inventors; Dey Laboratories Inc, assignee. Albuterol inhalation solution, system, kit and method for relieving symptoms of pediatric asthma. United States patent US 6,702,997. 2004 Mar 9.

2. Boulton DW, Fawcett JP. The pharmacokinetics of levosalbutamol: what are the clinical implications? Clin Pharmacokinet. 2001 Jan;40(1):23-40.DOI:10.2165/000 03088-200140010-00003

3. Maier G, Rubino C, Hsu R, Grasela T, Baumgartner RA. Population pharmacokinetics of (R)-albuterol and (S)-albuterol in pediatric patients aged 4-11 years with asthma. Pulmonary pharmacology \& therapeutics. 2007 Oct $1 ; 20(5): 534-42$.

4. Punj A, Prakash A, Bhasin A. Levosalbutamol vs racemic salbutamol in the treatment of acute exacerbation of asthma. Indian J Pediatr. 2009 Nov;76 (11): 1131-5. doi: 10.1007/s12098-009-0245-4.

5. Gupta MK, Singh M. Evidence based review on levosalbutamol. Indian J Pediatr. 2007 Feb;74(2):161-7.

6. Batra V, Niazi S, Peters SP. Persistent asthma: what approach is best? The focus of therapy is on inflammation. Journal of Respiratory Diseases. 2002 Jun 1;23 (6): 330-40.

7. Huang YJ, Nelson CE, Brodie EL, et al. Airway microbiota and bronchial hyper responsiveness in patients with suboptimally controlled asthma. J Allergy Clin Immunol. 2011 Feb;127(2):372-381.e1-3. doi: 10. 1016/j. jaci. 2010.10.048. Epub 2010 Dec 30.

\section{Original Research Article}

8. Lötvall J, Palmqvist M, Arvidsson P, et al. The therapeutic ratio of R-albuterol is comparable with that of RS-albuterol in asthmatic patients. J Allergy Clin Immunol. 2001 Nov;108(5):726-31.DOI:10.1067/mai. 2001. 119152

9. Handley DA, McCullough JR, Crowther SD, et al. Sympathomimetic enantiomers and asthma. Chirality. 1998;10(3):262-72.DOI:10.1002/(SICI)1520-636X (1998) 10:3<262:: AID-CHIR9>3.0.CO;2-B

10. Nowak RM, Pensler MI, Sarkar DD, Anderson JA, et al. Comparison of peak expiratory flow and FEV1 admission criteria for acute bronchial asthma. Ann Emerg Med. 1982 Feb;11(2):64-9.

11. Milgrom H, Berger W, Nayak A, et al. Treatment of childhood asthma with anti-immunoglobulin E antibody (omalizumab). Pediatrics. 2001 Aug;108(2): E36.DOI: 10. 1542 /peds.108.2.e36

12. Maiti R, Prasad CN, Jaida J, et al. Racemic salbutamol and levosalbutamol in mild persistent asthma: A comparative study of efficacy and safety. Indian J Pharmacol. 2011 Nov;43(6):638-43. doi: 10. 4103/ 0253-7613.89817.

13. Gawchik SM, Saccar CL, Noonan M, et al. The safety and efficacy of nebulized levalbuterol compared with racemic albuterol and placebo in the treatment of asthma in pediatric patients. J Allergy Clin Immunol. 1999 Apr;103(4):615-21.

14. Jantikar A, Brashier B, Maganji M, et al. Comparison of bronchodilator responses of levosalbutamol and salbutamol given via a pressurized metered dose inhaler: a randomized, double blind, single-dose, crossover study. Respir Med. 2007 Apr; 101(4): 845-9. Epub 2007 Feb 1.

15. Ameredes BT, Calhoun WJ. Modulation of GMCSF release by enantiomers of beta-agonists in human airway smooth muscle. J Allergy Clin Immunol. 2005 Jul;116(1):65-72. DOI:10.1016/j.jaci.2005.03.007

\section{How to cite this article?}

Sharma S, Mathew J.L, Singh M. Study of efficacy and safety of levosalbutamol versus racemic salbutamol delivered by metered dose inhaler in children with moderate persistent asthma. Int J Pediatr Res. 2019; 6(06):292-298.doi:10.17511/ ijpr.2019.i06.05 